\title{
Near infrared drying of pharmaceutical thin films: experimental analysis of internal mass transport
}

\author{
S. Le Person ${ }^{\mathrm{a}, \mathrm{b}}$, J.R. Puiggali a,*, M. Baron ${ }^{\mathrm{b}}$, M. Roques ${ }^{\mathrm{a}}$ \\ ${ }^{a}$ Laboratoire de Génie des Procédés de Pau (EAD 1932), ENSGTI, rue Jules Ferry, 64000 Pau, France \\ ${ }^{\mathrm{b}}$ Centre Poudres et Procédés, ENSTIMAC, 81013 Albi Cedex 09, France
}

\begin{abstract}
Thin polymer films are produced for pharmaceutical purposes from a solution in water and polar solvent. These coatings contain also a heavy solvent with the active substance as solute. A global analysis is presented here of the drying rate in terms of average content for each component, i.e. water, heavy solvent and active substance. The results are used to better the global drying process. The quality of the final product imposes to know the local distribution of the key products. The use of Laser Scanning Confocal Microscopy (LSCM) on two molecules is proposed here; the active substance and the heavy solvent. Combining the two set of results, one is able to determine the cases of maldistribution of the active substance and of eventual crystallisation which in turn will have consequences on storage and successful transdermal delivery of the drug.
\end{abstract}

Keywords: Drying kinetics; Coating; Selectivity; Laser Scanning Confocal Microscopy

\section{Introduction}

Modern industries produces more and more thin polymer films and coatings for many purposes, e.g. adhesives, varnishes and paints. In the pharmaceutical industry some films are used in patches for transdermal drug delivery. Drying is the essential unit operation necessary to form the final product. In all cases, mastering of process variable and microscopic aspects of the product quality entails chemical and process engineering and transport phenomena as basic sciences.

After preparation, the coating mixture is spread on a web and submitted to drying in a tunnel or an oven. Frequently, impinging jets and Infra Red Radiation [1] accomplish the work in a short drying time (100 s as an order of magnitude). In the end, one must be sure that the selected process and its conditions is able to ensure the right product quality; a limited remanence of the process solvent (generally a mixture of volatile solvents) and a given quality product [2], i.e. physical and chem-

\footnotetext{
* Corresponding author. Tel.: + 33597 22080; fax: + 33559 722081; e-mail: jean-rodolphe.puiggali@univ-pau.fr
}

ical homogeneity and an appropriate distribution of active substance.

The tools to design the correct process are pilot plant experiments, bench scale experiments and modelisation of transfers. In this paper, small scale experiments were opted for and an experimental approach of internal transfers. Evidently, the diffusional approach of complex systems containing two immiscible solvents, a shrinking polymeric macromolecule network and an active substance, cannot be tracked from the basic text-book equations. What is modelisable is already intuitively and/or experimentally known. It would take a lot of basic investigation on simpler systems to make a substantial progress on the only problem of cross diffusivities [3]. For all those reasons it has been suggested, in this paper, to track the internal distribution of some key products by Laser Scanning Confocal Microscopy (LSCM). Adding an integral chemical analysis of the film, one is then able to quantify the absolute distribution for films produced under variable conditions.

After few other investigators [4,5], the use of LSCM for films was advocated because this technique eliminates all informations in the depth but the one from a specific plane. By moving vertically the sample or the 
Typical wet composition of the coating

\begin{tabular}{|c|c|c|c|c|c|c|}
\hline & \multirow[t]{2}{*}{ Acrylic polymer (Pol) } & \multicolumn{3}{|c|}{ Light solvents } & \multirow{2}{*}{$\begin{array}{l}\text { Active phase } \\
\text { Excipient heavy solvent (E) }\end{array}$} & \multirow[b]{2}{*}{ Active substance (PA) } \\
\hline & & $\mathrm{Sl}_{1}$ & $\mathrm{Sl}_{2}$ & $\mathrm{Sl}_{3}$ & & \\
\hline Typical composition (100 g) & 52 & 38 & 3 & 4 & 2 & 1 \\
\hline
\end{tabular}

objective, one gets a resolution of ca. $1 \mu \mathrm{m}$. Not all the molecules are susceptible to be excited by laser beam but we were fortunate to have two in our sample and could then reconstruct all interesting distribution.

The release kinetics of a drug by application onto the skin depends on the appropriate distribution of the drug which in turn depends on the drying process. Hence the selection of a process is based upon the thermosensitivity of the active substance and a homogeneous treatment of the film [6]. It appeared that after a rapid screening that SIR plus convection was the best solution. It is proposed in this paper to validate this first guess by an analysis in depth of the product quality.

\section{Materials and experiences}

\subsection{Product composition}

The coating mixture is constituted of: (1) an acrylic adhesive polymer (Pol); (2) three light solvents $\left(\mathrm{Sl}_{\mathrm{i}}\right)$; (3) one heavy solvent named hereafter excipient $(E)$; (4) one pharmaceutical active substance (AS) reputedly soluble in $E$. As excipient is essential to the administration of the drug, the drying process must evacuate the light solvent and preserve a maximum amount of $E$, hence the selectivity requirement. A typical wet coating composition is given in Table 1 together with the molecular weight of the essential products.

The final composition of the coating for each of the solvents, excipient and active substance is also part of the industrial target, the mass distribution within the thickness of the coating was added to this ordinary constraint; these two pieces of information have to be analysed as selective drying. Moreover during drying process the thermal degradation of the active substance must be avoided.

\subsection{Experimental set-up}

In order to substantiate the choice of the best heat supply mode with respect to drying time and quality, the coating drying were studied by convection, conduction, medium and short infra-red respectively (MIR and SIR), each of the last drying modes is always associated with convection. Experiments were carried out in a laboratory set-up mainly composed of two parts, the drying cell and the wind tunnel (see Fig. 1):

- the wind tunnel is a conventional drying rig where temperature $\left(T_{\infty \mathrm{db}}\right)$, velocity $\left(U_{\infty}\right)$, and humidity $\left(Y_{\infty}\right)$, of air are controlled,

- in the drying cell the sample weight is continuously recorded; depending on the combined heat supply, a heated slab $\left(T_{\mathrm{c}}\right)$, non heated in the case of pure convection, can support the sample (conduction) or an infrared emitter (MIR or SIR) can irradiate $\left(P_{\mathrm{IR}}\right)$ from a given height $(h)$ the sample.

Operating conditions for the different experiments to qualify quality with respect to heat supply are summarised in Table 2.

\subsection{Drying kinetics}

During those experiments the mass of the sample is either continuously recorded or acquired at regular intervals. Moreover the average composition is determined on partially dried coatings by means of chromatographic analysis and coulometry. Then, each point of a curve corresponds to a separate drying experiment carried out at least twice. The initial coating thickness for all the tests was $200 \mu \mathrm{m}$.

Drying kinetics reported on Fig. 2 show that the initial drying velocity with infrared is about twice the velocity with other heating modes. Source thermal inertia affects greatly the first two points of the MIR drying curve bringing an abnormal delay. Between conduction and SIR the latter one is far more preferable.

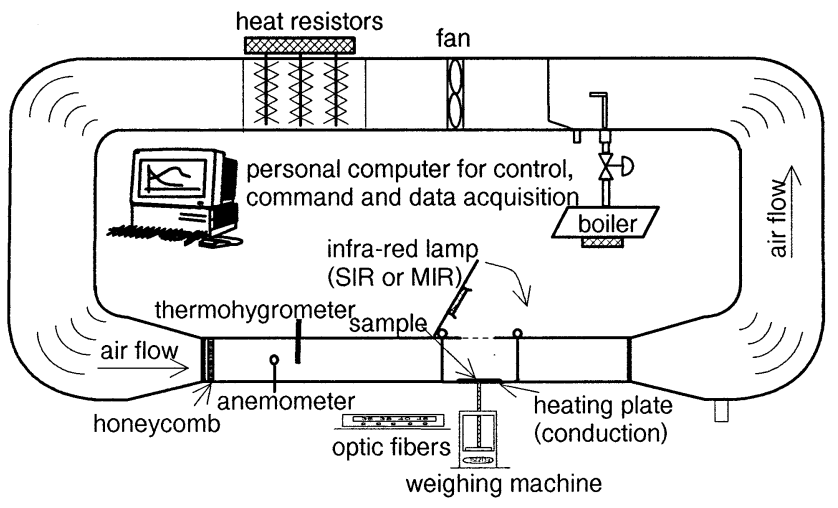

Fig. 1. Schematic view of the experimental set-up. 
Table 2

Typical wet composition of the coating

\begin{tabular}{ll}
\hline Heat supply & Operating conditions \\
\hline IRC & $P_{\mathrm{IR}}=170 \mathrm{~W} ; h=5 \mathrm{~cm} ; U_{\infty}=2 \mathrm{~m} / \mathrm{s} ; T_{\infty \mathrm{db}}=$ \\
& $30^{\circ} \mathrm{C} ; T_{\infty \mathrm{wb}}=18^{\circ} \mathrm{C}$ \\
IRM & $P_{\mathrm{IR}}=140 \mathrm{~W} ; h=6 \mathrm{~cm} ; U_{\infty}=2 \mathrm{~m} / \mathrm{s} ; T_{\infty \mathrm{db}}=$ \\
& $30^{\circ} \mathrm{C} ; T_{\infty \mathrm{wb}}=18^{\circ} \mathrm{C}$ \\
Conduction & $T_{\mathrm{c}}=60^{\circ} \mathrm{C} ; U_{\infty}=4 \mathrm{~m} / \mathrm{s} ; T_{\infty \mathrm{db}}=65^{\circ} \mathrm{C} ; T_{\infty \mathrm{wb}}=$ \\
& $44^{\circ} \mathrm{C}$ \\
Pure convection & $U_{\infty}=4 \mathrm{~m} / \mathrm{s} ; T_{\infty \mathrm{db}}=75^{\circ} \mathrm{C} ; T_{\infty \mathrm{wb}}=36^{\circ} \mathrm{C}$ \\
\hline
\end{tabular}

Analytical results on films show that the various heating processes can be classified by the remaining ratio of solvents to dry matter $\left(\mathrm{Sl}_{\mathrm{i}}+E\right) / \mathrm{Pol}$, by the ratio of heavy solvent to water $E / \mathrm{Sl}_{1}$ and by the drying time. In Table 3 it is shown that SIR is vastly preferable in order to keep the heavy solvent inside the product in the minimum drying time. The ratio $\left(\mathrm{Sl}_{\mathrm{i}}+E\right) / \mathrm{Pol}$ is not discriminant.

\subsection{Temperature during SIR drying}

Although rapid, and quality respectful, the SIR drying might harm the product because of local over heating. In order to evaluate this danger, It was realised that a thermal study of the coating for different infrared powers, for different thickness and coating supports.

Three thermocouples were embedded in a thick coating of $2-15 \mathrm{~mm}$, an extrapolation of the temperature profile towards the irradiated surface permits to evaluate the highest temperature obtained by irradiation for various drying times and constant infrared power (see Fig. 3).

From Fig. 3, one can infer that $65^{\circ} \mathrm{C}$ is the maximum temperature reached at the end of the drying process and hence nor alteration nor destruction is to be feared

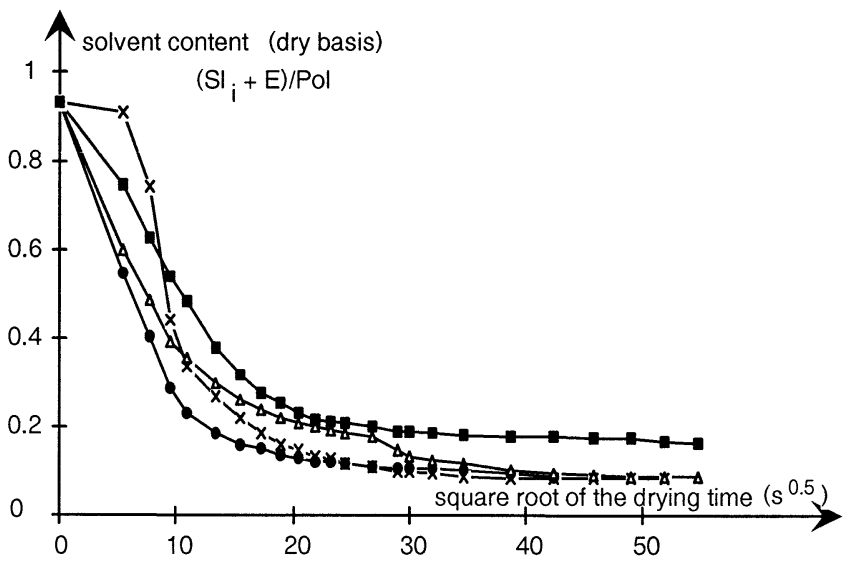

Fig. 2. Drying kinetics of a $200 \mu \mathrm{m}$ thick coating under four drying different processes: pure convection $(\mathbf{\square})$, combined process: convection plus MIR (x), $\operatorname{SIR}(\bullet)$, conduction $(\triangle)$.
Table 3

Final composition indicators for different heating modes

\begin{tabular}{lllll}
\hline Indicators & SIR & MIR & Conduction & $\begin{array}{l}\text { Pure convec- } \\
\text { tion }\end{array}$ \\
\hline $\begin{array}{l}\text { Mass ratio } \\
\left.\quad \mathrm{S} 1_{\mathrm{i}}+E\right) / \text { Pol }\end{array}$ & $\approx \mathrm{X}$ & $0.8 \mathrm{X}$ & $\approx 0.8 \mathrm{X}$ \\
$\begin{array}{l}\text { Mass ratio } E / \\
\quad \mathrm{Y}\end{array}$ & $0.9 \mathrm{Y}$ & $0.5 \mathrm{Y}$ & $0.6 \mathrm{Y}$ \\
$\begin{array}{l}\mathrm{Sl}_{1} \\
\text { Drying time } \\
\text { range }\end{array}$ & & & \\
\hline $\mathbf{t}$ & & & \\
\hline
\end{tabular}

according to the stability diagram of the active substance. Similar results have been obtained by optic pyrometry on similar coatings (acrylic polymers) by Navarri and Andrieu [7].

It was concluded that SIR drying is the appropriate answer to the drying time and quality constraints.

\subsection{Thermodynamic of the active phase}

During the drying process the thin layer temperature increases as the solvent contents decrease. At the end of the process the coating is cooled at a given AS mass fraction. All these changes in temperature and composition mass and thermal steps are susceptible to produce active substance crystallisation in the thin film and therefore the final quality of the product might be out of bonds. A good knowledge of solubility behaviour of the active substance in the heavy solvent is necessary to avoid this arowback. An analysis of the solvent mass loss coupled with the coating temperature increase is a good tool to propose drying schedules in relation with dried product quality.

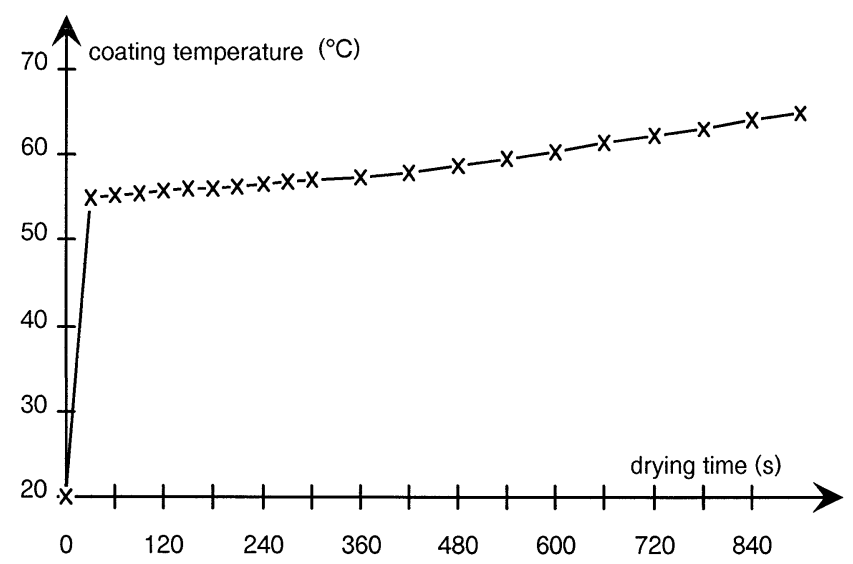

Fig. 3. Averaged temperature of a $100 \mu \mathrm{m}$ thick coating under Short Infra Red drying (Table 2) obtained by extrapolation of experimental results on $2-15 \mathrm{~mm}$ thick coatings. 


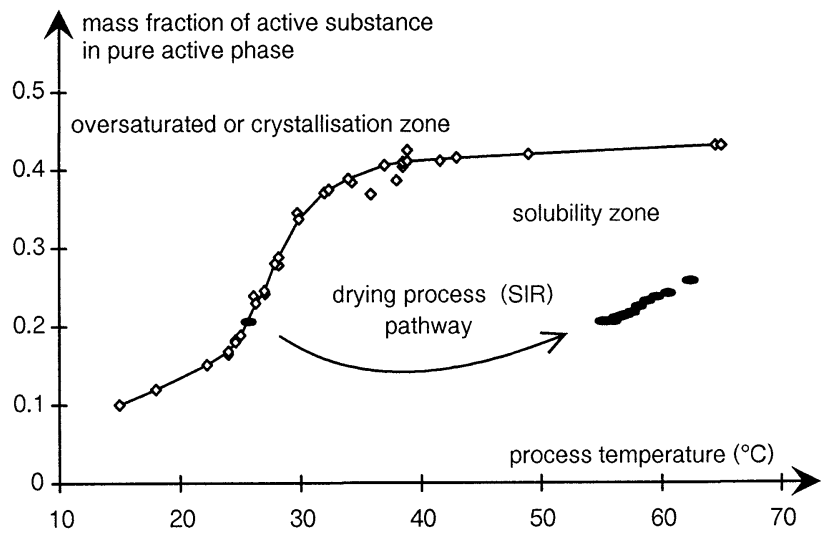

Fig. 4. Active substance solubility curve in the active phase (heavy solvent plus active substance) obtained by cooling of a solution initially at $70^{\circ} \mathrm{C}$ by air at $15^{\circ} \mathrm{C}$.

Solubility of the active substance in the heavy solvent is obtained by cooling (ambient air flow) of the active phase solution at a given mass fraction $\left(M_{\mathrm{AS}} / M_{\mathrm{AS}}+\right.$ $M_{\mathrm{E}}$ ) initially unsaturated and homogenised at $75^{\circ} \mathrm{C}$ with ultra sounds. A thermocouple placed in the solution allows to follow the temperature evolution and, linked with an observation of active substance crystals through a microscope, the saturation temperature is obtained and the solubility curve plotted (Fig. 4).

On the same graph, the AS mass fraction is plotted versus temperature as the SIR drying process of the heavy phase $E$ proceeds. One can notice that no crystallisation problem occurs if the mass fraction is considered in terms of an average value.

In order to show some light on the selective character of the drying operation, purpose of which is not just to remove the moisture, a more accurate study is necessary. Therefore, in relation with the quality and the final product requirements, one has to investigate, more precisely than an average kinetics study, the repartition of the active phase components (heavy solvent and active substance) inside the thin film.

\section{Results}

\subsection{Time evolution of components}

In order to follow the evolution in mass of each component during drying, there is only one way; repeat a given experiment as many times as you need an analysis. This regular dosage is carried out by liquid and gas chromatography and also by coulometry, (complete analysis every $30 \mathrm{~s}$ ); results are given on Fig. 5.

Using the selectivity coefficient $S_{i}$ of a component $i$ in a solution as defined by Riede and Schlünder [8] and used by Wolf [9] for hygroscopic materials: $S_{\text {solvent } i}=$

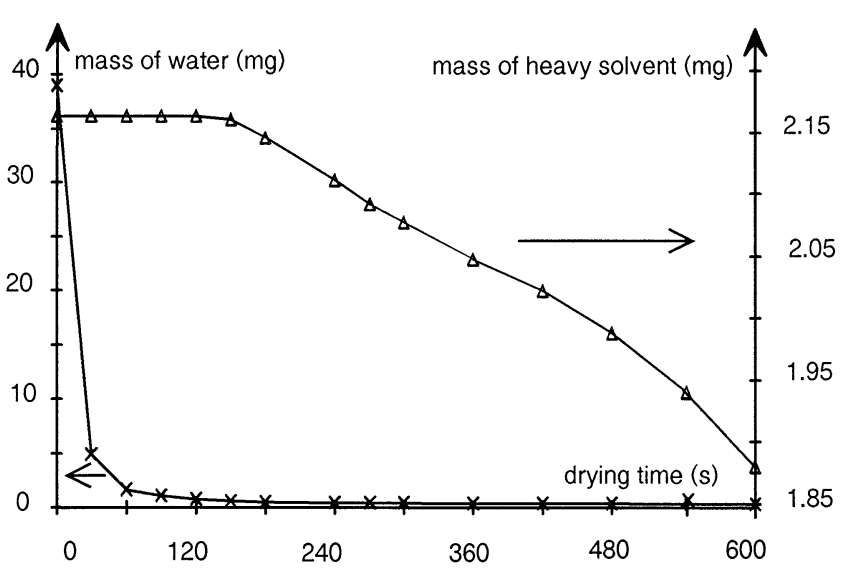

Fig. 5. Mass evolution of each components during drying kinetics of a $100 \mu \mathrm{m}$ thick coating under Short Infra Red drying process.

$\frac{n_{\text {solvent } i}}{n_{\text {all solvents }}}-x_{\text {solvent } i}$, one can evaluates the drying efficiency with respect to water and heavy solvent. In this last relation, $n_{\mathrm{i}}$ is the evaporative mass flux of solvent $i$, $n_{\text {all solvents }}$ the total evaporative mass flux and $\mathrm{ix}_{\mathrm{i}}$ the mass fraction of the solvent $i$. As indicated in Fig. 6, where $S_{\text {water }}$ and $S_{\text {heavy solvent }}$ are plotted versus drying time, water evaporates preferentially, regarding to the heavy solvent, at the beginning of the drying process. The thin film thickness is also plotted on this figure showing that shrinkage occurs essentially when water (major solvent) intensely evaporates [10,11].

In Fig. 5 the selective character of drying is demonstrated since $99 \%$ of the initial water amount is evaporated in $10 \mathrm{~min}$. In the same time only $2.05 \%$ of heavy solvent evaporates; this last evaporation is due to the absence of heavy solvent vapour in the drying air. An important practical consequence of this heavy solvent evaporation is that one must shorten the drying time to maintain most of this solvent inside the product.

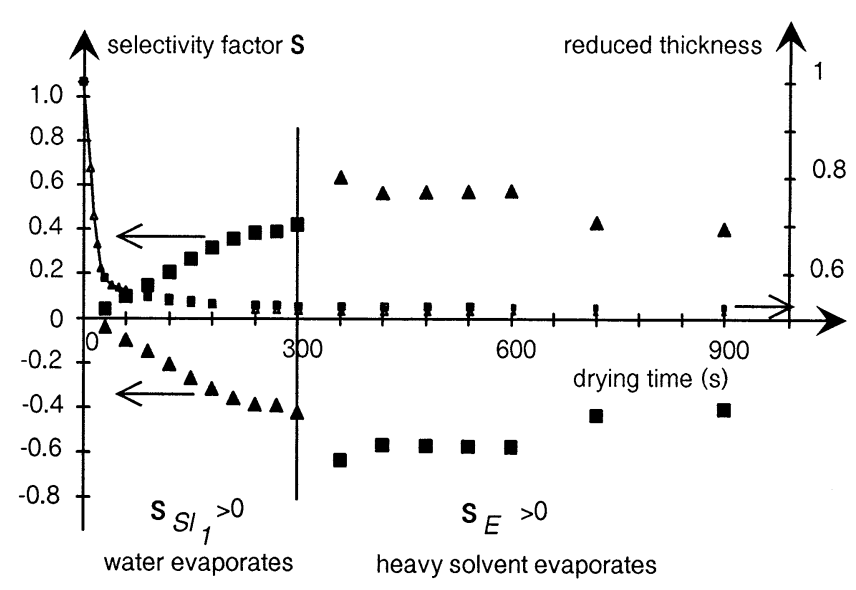

Fig. 6. Selectivity factors for the two major solvents, i.e. water $\left(\mathrm{Sl}_{1}\right.$ Ш) and heavy solvent $(E \boldsymbol{\Delta})$ during drying of a $100 \mu \mathrm{m}$ thick coating under Short Infra Red drying process. Indication of the shrinkage in terms of reduced thickness. 
So far there are only global results that is to say drying curves for each component of the coating. The results are valuable for a good management of the drying operation but failed to give detailed informations on the quality of the product. Again, precise knowledge of the spatial repartition component in the volume is completely necessary to assess the functionality of the final product.

A new non destructive exploration method has been used, tested and validated in order to follow the spatial distribution of the components of the active phase. Laser Scanning Confocal Microscopy (LSCM) can provide this type of informations in as much as the probe molecule is fluorescent under laser beam radiation.

\subsection{Spatial evolution of the components}

The LSCM allows, without sample preparation, the observation of a given surface called focal surface inside the thickness of the sample, avoiding the destructive slicing, with a much better resolution. Precisely, with a micronic resolution one is able to obtain accurate data on very thin sub-millimetric films.

The principle feature of confocal imaging is that detection is strictly limited to what is in focus; LSCM avoids out-of-focus informations from neighbouring planes.

The substance is irradiated by a laser beam. An intensity of fluorescence, proportional to the quantity of excited substance in the focus plane, is the information in return. Only aromatic molecules and/or elements with double conjugated links are excited by laser beam UV (364) or Visible $(633,543,488)$. A map of the average fluorescence relative to the studied component can be obtained on the focus plane. By displacement of the focus plane, one can follow the fluorescence intensity of the component in the thickness of the sample [12].

Studies were carried out, with the help of Dr Catherine Garnier, at the Macromolecule Physico-Chemistry Laboratory (LPCM-INRA) at Nantes (F). All fluorescence measurements were performed using a microscope Axiovert 135M-Zeiss, an UV 364-Microsysteme laser as the excitation source and a SLM-Zeiss as spectrofluorimeter.

A miniature drying ring obviously had to be brought consisting of the infrared lamp and a blower in the vicinity of the LSCM microscope. Each sample was dried, on a glass plate, for a given length of time $(5,10$, $15 \mathrm{~min}$ ) then sealed over by a plastic film, brought to the microscope and analysed for $120 \mathrm{~s}$ during which the relaxation processes are unavailable but limited.

In parallel a chemical dosage allows the determination of the total mass of the fluorescent element in the studied substance. Therefore it is easy to connect the

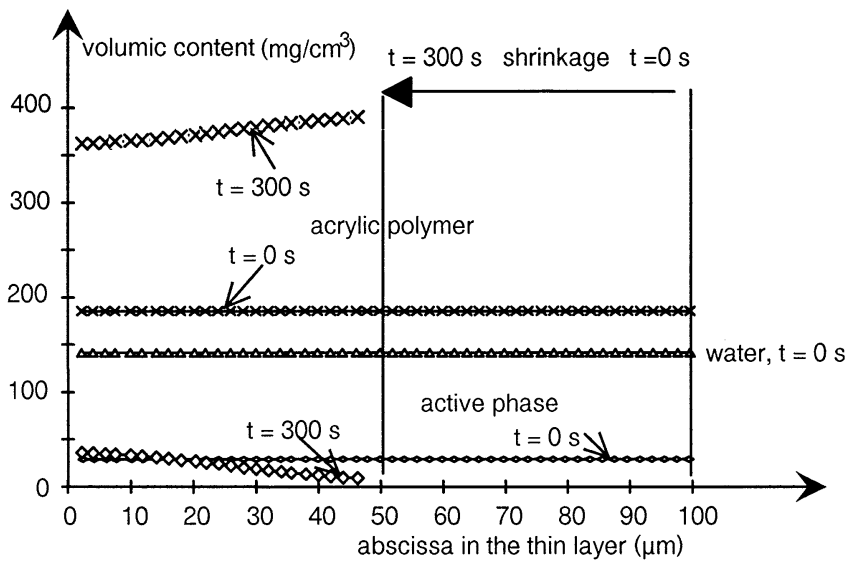

Fig. 7. Volumic contents of the water, active phase and polymer during drying of a $100 \mu \mathrm{m}$ thick coating under Short Infra Red drying process. Indication of the shrinkage in terms of coating thickness before drying and after 5 min of drying.

fluorescence informations to quantitative data.

Amongst the constitutive elements of the enduction, only the active substance and the heavy solvent can be excited by a UV364 laser beam.

After the disappearance of water from the thin layer, no further shrinkage occurs and the film consists of polymer and active phase (heavy solvent and active component) the volume of which are simply additive.

It is obvious then to calculate the spatial distribution of the polymer, knowing that of the others components.

\section{Discussion}

Because of the fluorescence of the two constituents of the active phase, an analysis of many preparations, with different concentrations, is necessary before studying the real enduction in order to differentiate the respective impact both of the active substance and of the heavy solvent.

Observations were carried out on enductions after 5, 10 and $15 \mathrm{~min}$ of drying. Before drying an observation is made in order to assess the degree of homogeneity of the constituents inside the thin layer.

After a 5 min drying analytical dosages (Fig. 5) show that only three components remain in the layer: (1) acrylic polymer; (2) active substance; and (3) heavy solvent. As the thin layer shrinkage is known (Fig. 6), one can transpose the LCSM data in terms of volumic content fields (Fig. 7). The intense moisture removal, through the exposed surface of the layer to the radiation, during the first 3 min of drying (Fig. 7) produces a stress on the polymer skeleton. This stress increases in the water flow direction and as a result the acrylic polymer becomes more and more dense in the upper part of the layer (exposed surface). This intense shrinkage coupled with the polymer compaction causes a displacement of the active phase towards the bottom of the layer (Fig. 7). 


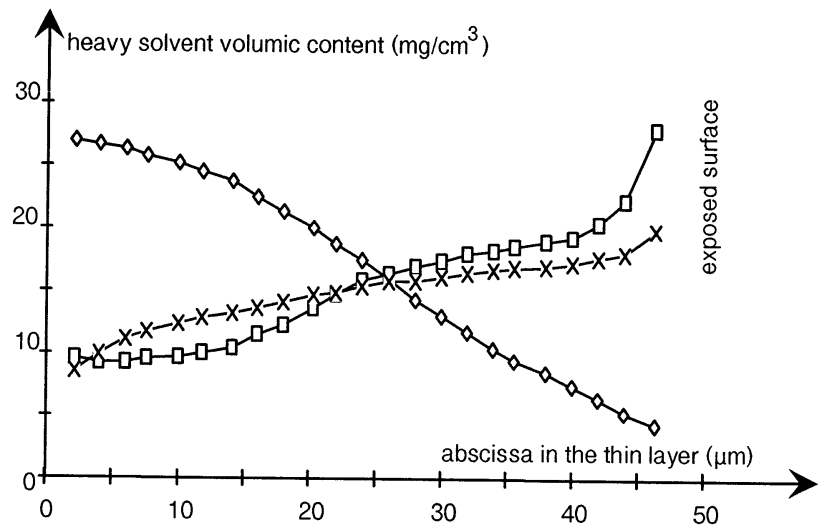

Fig. 8. Volumic content fields of the heavy solvent at three drying times $(300 \diamond, 600 \square, 900 \mathrm{~s} \mathrm{x})$ during drying of a $100 \mu \mathrm{m}$ thick coating under Short Infra Red drying process.

This instantaneous view of the volumic content fields for the thin layer constituents show a very unstable state. One can easily imagine that the compressive wave must propagates from the top to the bottom of the enduction. Therefore at the end of the drying process the global skeleton structure will be equilibrated.

During the thin layer drying, two main stages are identified on Figs. 8 and 9 where the spatial evolution of the heavy solvent and the active substance are reported after 5, 10, 15 min of drying:

a first stage ( $t \leq 5 \mathrm{~min}$ for the drying condition), where water is intensively removed producing a severe shrinkage of the layer and a compaction of the polymeric skeleton at the top (in fact the exposed surface); as a result, the active phase in solution in the heavy solvent is displaced towards the bottom, a second stage where the volumic content fields of each component equilibrate themselves in the layer due to the combined displacement of the solvent and the relaxation of the polymer skeleton; the discharge of the polymer towards the bottom giving a stable

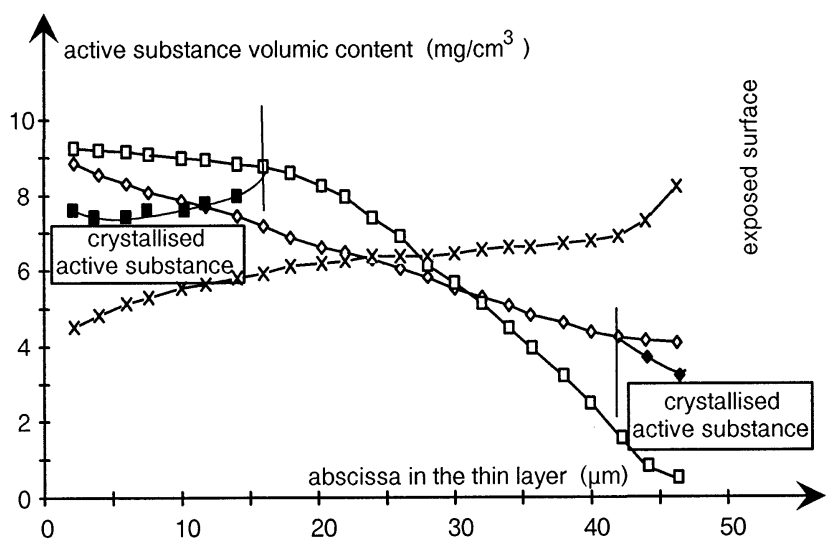

Fig. 9. Volumic content fields of the active substance at three drying times $(300 \diamond, 600 \square, 900 \mathrm{~s} \mathrm{x})$ during drying of a $100 \mu \mathrm{m}$ thick coating under Short Infra Red drying process.

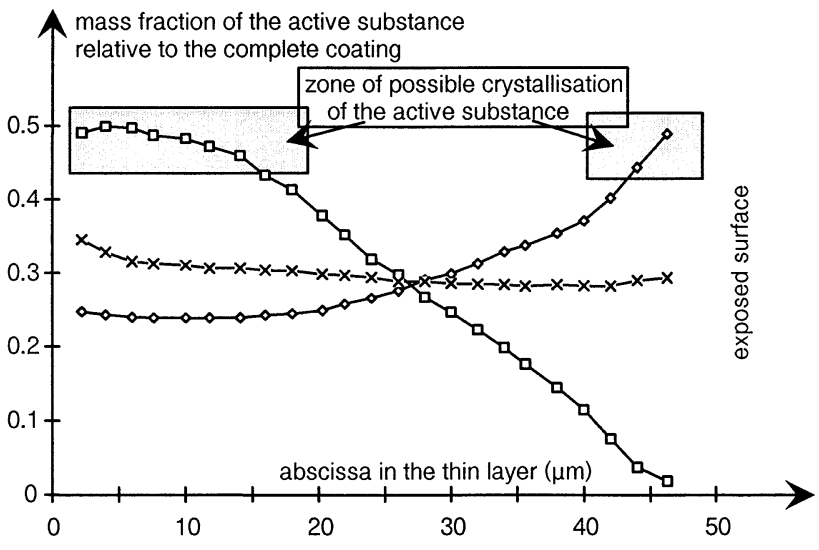

Fig. 10. Mass fraction fields of the active substance at three drying times (300 $\diamond, 600 \square, 900 \mathrm{~s}$ x) during drying of a $100 \mu \mathrm{m}$ thick coating under Short Infra Red drying process. Indications of the possible zones of crystallisation.

mechanical state is joined to a movement from bottom to top of the active phase with a partial removal of the heavy solvent.

Initially, in the thin layer the constituents of the active phase are homogeneously distributed. But the pharmaceutical active substance has a larger steric bulk than the heavy solvent and therefore might react differently to the stresses imposed by the skeleton of the acrylic polymer during the drying process. Then a detailed study of the spatial evolution of the active substance constituents must be carried out in order to prevent risks of separation of the active substance from the active phase.

Combining measurements made by LCSM and solubility data (Fig. 4) of the active substance in the heavy solvent lead one to suppose the existence of the active substance in its crystalline form. This is true for the residual quantity of the active molecules trapped in the retracted skeleton of the adhesive polymer $5 \mu \mathrm{m}$ under the exposed surface (Fig. 10).

After $5 \mathrm{~min}$ of drying the system tends to reequilibrate the mechanical stresses. However, because water is no more present in the system, the polymeric network is not turgescent and the meshes are densely packed. The polymer skeleton acts as a filter for the active substance when the system reequilibrates. By their respective mobility and bulk, the heavy solvent will slip easier than the active substance through the net during this phase of mechanical reequilibrium just as in thin layer chromatography.

Consequently, after 10 min of drying, one can notice (Figs. 8 and 9) an inversion of the heavy solvent and active substance concentration profiles inside the enduction. Between the 5th and the 10th min of drying the heavy solvent migrates towards the exposed surface and is removed whereas the active substance, slowed down in its migration, stays in the bottom of the layer. 
Because of a quicker migration effect than the evaporation one the heavy solvent is stored in the top of the coating. The lack of heavy solvent with respect to the active substance in the bottom of the layer should lead to find, in this location, an important crystallisation. This is shown in Fig. 10 where crystallisation is indicated on a $15 \mu \mathrm{m}$ thickness in the bottom of the layer.

As the drying process proceeds, the active substance, from its strong affinity with the heavy solvent migrates and homogenises in the enduction thickness. After 15 min of drying, a quasi equilibrium is obtained for the components of the active phase, taking into account the evaporation of the heavy solvent.

\section{Conclusion}

The coupling between studies performed, on the one hand on a temporal basis (chromatographic and coulometric analysis), and on the other hand on a spatial basis (LSCM) allows to propose a model of the constituent transports inside the film whose thickness shrinks from 100 to $50 \mu \mathrm{m}$ during drying.

The schematic description of the behaviour of the acrylic polymer and the solubility curve of the active substance in the heavy solvent allow to explain and to prevent mechanisms of separation of the active phase in the layer thickness. Such separation effects can produce harmful crystallisation phenomena.

These studies on overall and local behaviour of each components of the pharmaceutical thin film are fully sufficient in order to propose drying schedules. Following these lines and the guide suggested by Nadeau and Puiggali J.R. [13], a pilot plant for thin pharmaceutical layer drying was designed [14].

\section{References}

[1] E.D. Cohen, E.J. Lightfoot, E.B. Gutoff, A primer on forming coatings, Chem. Eng. Prog. September, (1990) 30-36.

[2] Z.W. Wicks, F.N. Jones, S.P. Pappas, Organic coatings: science and technology, vol. 1: Film Formation, Components and Appearance, Wiley, New York, 1992, pp. 343.

[3] R. Taylor, R. Krishna, Multicomponent Mass Transfer, Wiley, New York, 1993, p. 579.

[4] H. Verghoot, J. van Dam, P. de Boer, A. Draaijer, M. Houpt, Confocal laser scanning microscopy: a new method for determination of the morphology of polymer blends, Polymer 34 (6) (1993) $1325-1329$.

[5] L. Li, S. Sosnowski, C.E. Chaffey, S.T. Balke, M.A. Winnik, Surface morphology of a polymer blend examined by laser confocal fluorescence microscopy, Langmuir 30 (8) (1994) 24952497.

[6] R.O. Potts, G.W. Cleary, Transdermal drug delivery: useful paradigms, J. Drug Targeting 3 (1995) 247-251.

[7] P. Navarri, J. Andrieu, High intensity infrared drying study. Part I. Case of thin coated films, Chem. Eng. Process. 32 (1993) $319-325$.

[8] T.H. Riede, E.U. Schlünder, Selective evaporation of a ternary mixture containing one nonvolatile component with regard to drying processes, Chem. Eng. Process. 28 (1990) 151-163.

[9] H. Wolf, Selective drying of hygroscopic materials wetted with binary mixtures, Drying Technol. 12 (6) (1994) 1445-1470.

[10] W. Aregba, W. Jomaa, J.R. Puiggali, Une approche du séchage de matériaux fortement déformables, Rev. Phys. Appl. 25 (1990) $1161-1175$.

[11] M. Moyne, N. Kechaou, P. Do Amaral Sobral, M. Roques, A. Cairault, H. Bizot, Mechanism of water transport in drying gels, Int. Chem. Eng. 34 (3) (1994) 360-369.

[12] H. Jinnai, Y. Nishikawa, T. Koga, T. Hashimoto, Direct observation of three-dimensional bicontinuous structure developed via spinodal decomposition, Macromolecules 28 (13) (1995) 47824784.

[13] J.P. Nadeau, J.R. Puiggali, De l'analyse d'un produit à la conception d'un séchoir, Entropie 49 (1982) 41-47.

[14] S. Le Person, Séchage Sélectif d'Enductions Pharmaceutiques, $\mathrm{PhD}$ thesis, Université de Pau et des Pays de l'Adour (F), 339 (1996) 187. 